\title{
AUTUMN COPULATORY BEHAVIOR IN CALIFORNIA QUAIL: OBSERVATIONS AND POTENTIAL FUNCTIONS
}

ALLISON M. ROTH, Department of Biology, University of Florida, Gainesville, Florida 32611; amr2264@columbia.edu

JENNIFER M. GEE, James San Jacinto Mountains Reserve, University of California - Riverside, University of California Natural Reserve System, Idyllwild, California 92549

CARL N. KEISER, Department of Biology, University of Florida, Gainesville, Florida 32611

ABSTRACT: Most birds living in the temperate zones breed in spring or summer. In a variety of species, however, copulatory behavior has been observed out of season in autumn. Such activity has been proposed to represent late breeding attempts, help to maintain pair bonds during the nonbreeding season, or aid in the formation of future breeding pairs. We observed three attempted copulations (one with cloacal contact) in late November between three male and two female California Quail (Callipepla californica), a species with a flexible mating system. Given that one of the females, and at least two of the observed males, were under a year of age and, therefore, almost certainly sexually immature, we suggest that these copulation attempts could contribute to pair formation. The two males and two females, whose identities were known, spent more time associating with the individual with which they engaged in copulatory activity than with any other covey member of the opposite sex, also implying a social function of this behavior. Nevertheless, we cannot rule out the unlikely possibilities that the observed activity represented astonishingly early breeding attempts, acted as expressions of intersexual social dominance, or functioned as practice for the upcoming breeding season. Possibly, the behavior served no immediate adaptive purpose. Nevertheless, autumn copulatory activity in the California Quail may be more common than known, and we present these observations as a call for further monitoring to clarify the potential function(s) of this behavior.

Some avian species living in temperate climates have been reported to copulate during the autumn and/or winter, outside of their regular breeding season (Höhn 1947, Marshall 1952, Snow 1955, Orians 1960). In males, this out-of-season copulatory activity may arise as a result of a regeneration of interstitial cells in the testes, following a refractory period after the spring breeding season (Marshall 1952). Moreover, autumn or winter copulatory behavior may reflect late breeding attempts, assist in pair formation, or help to maintain pair bonds between previously mated birds during the nonbreeding season (Höhn 1947, Marshall 1952).

Koenig and Stahl (2007) discovered that, among the 441 North American terrestrial birds they evaluated, nesting activity (i.e., laying or incubation) between 1 September and 30 November had been reported at least once in $\sim 16 \%$ (i.e., 69 species). Of these, 66 species breed primarily in the spring or summer, providing support that autumn copulatory behavior may reflect late breeding attempts (Koenig and Stahl 2007). Koenig and Stahl (2007) found that late nesting was more common among resident species than among migrants, and among species that nest colonially or semicolonially than among solitary nesters. Late nesting may arise as a result of natural or anthropogenic 
environmental conditions such as warmer temperatures, irregular periods of abundant food, heavy or unpredictable precipitation, or changes in habitat type (MacGregor and Inlay 1951, Snow 1955, Orians 1960, Selander and Nicholson 1962, Ostfeld and Keesing 2000, Koenig and Stahl 2007).

In addition to potential reproductive purposes, copulatory behavior in autumn or winter may serve to assist in the formation of new pairs or help maintain pair bonds during the nonbreeding season (Höhn 1947, Marshall 1952, Spurr and Milne 1976). Pair bonding in the nonbreeding season may confer advantages such as earlier or increased reproductive synchrony of mated pairs, increased winter survival, or reduced partner loss due to death or divorce (Butterfield 1970, Rowley 1983, Ens et al. 1996, Kellam 2003, Culina et al. 2015). When copulatory activity aids in pair-bond maintenance or formation, in some species, copulatory behaviors in the breeding and nonbreeding seasons may differ mechanistically. For example, although copulatory activity has been observed in waterfowl during the winter, when pair bonding occurs, such activity differs from copulations within the breeding season, as males are unable to evert their penis during the pair-bonding phase (Höhn 1947, Brennan and Prum 2012).

The California Quail (Callipepla californica; Figure 1) is a nonmigratory sexually dichromatic species with sex-specific social hierarchies (Leopold 1977, Calkins et al. 2014). During the nonbreeding season, it lives in stable social groups, termed coveys (Leopold 1977, Calkins et al. 2014). Coveys typically range in size from 27 to 79 individuals but can get much larger, rarely even exceeding 1000 individuals (Sumner 1935, Leopold 1977, Calkins 2000, Calkins et al. 2014). Annual mortality of adults ranges from $59 \%$ to $77 \%$, with the oldest reported wild individual having lived to an age of at least 6.5 years (Raitt and Genelly 1964, Leopold 1977, Calkins et al. 2014). Quail of both sexes reach sexual maturity at the age of 10 months, directly before their first breeding season (Leopold 1977). During the breeding season, individuals may follow a variety of mating strategies including social monogamy, simultaneous polyandry, sequential polyandry, and sequential polygamy (Leopold 1977, Calkins et al. 2014). Facultative inter- and intraspecific brood parasitism and communal rearing of young are also known (Leopold 1977, Lott and Mastrup 1999, Krakauer 2003, Calkins 2007, Calkins et al. 2014). In a mixed-species population in the zone where the California Quail and Gambel's Quail ( $C$. gambelii) hybridize, resident quail lay more eggs and hatch more chicks, which hatch on earlier mean dates, than do quail that overwinter in nonresident coveys (Gee 2003). Interestingly, when male and female California Quail were implanted with testosterone or synthetic estrogen, respectively, during the nonbreeding season, they formed pairs but did not exhibit any copulatory activity or courtship behavior (Emlen and Lorenz 1942, Adkins-Regan 2005).

Copulations are seldom seen in wild California Quail, given this species' elusiveness, and much of the evidence we have regarding the timing of reproduction in natural populations is inferred from dates of laying and observations of coveys' break-up. Quail breed primarily with members of their own covey, and females typically raise a single brood (but may raise two broods in productive years; McMillan 1964, Francis 1965, Anthony 1970, Leopold 1977, Calkins et al. 2014). Although the breeding season varies by locality and is influenced by environmental factors such as temperature and precipi- 
tation, the majority of breeding occurs in the spring, sometime between late February/March and June (Sumner 1935, Leopold 1977, Calkins et al. 2014). Nevertheless, September clutches have occasionally been observed in the California Quail and its sister species, the Gambel's Quail (Koenig and Stahl 2007; Western Foundation of Vertebrate Zoology, collection searched 2020 at https://collections.wfvz.org). Additionally, there has been a single sighting of a brood of California Quail chicks, believed to be $\leq 10$ days old, in early January, implying laying in early December (Compton 1931). Despite this, there seem to be no direct observations of autumn copulatory activity in California quail.

Here, we report data on several attempted November copulations in a covey of individually color-banded wild California Quail in the Anza-Borrego Desert in California. Both the age and social associations of these birds shed light on the potential functions of autumn copulatory activity in this species.

\section{METHODS}

From 15 to 29 November 2019, Roth observed a covey of wild California Quail daily between 05:30 and 16:30 Pacific Standard Time from the roof of a private home $\left(33.233^{\circ} \mathrm{N}, 116.389^{\circ} \mathrm{W}\right.$; Figure S1; see https://archive. westernfieldornithologists.org/archive/V52/Roth_Appendix) in the community of Borrego Springs, California $\left(33.233^{\circ} \mathrm{N}, 116.389^{\circ} \mathrm{W}\right)$. Earlier in the month, with the help of field assistants, Roth and Gee had trapped the birds with seed-baited walk-in funnel traps. They sexed, aged, measured, and banded the birds for individual recognition with a unique combination of a single numbered aluminum band and one to three colored Darvic plastic bands. We assigned an age of $<1$ year if a bird retained mottled primary coverts and an age of $>1$ year if the primary coverts lacked mottling (Williams 1959; Figure 2). Roth observed the covey roosting daily in a large Jojoba (Simmondsia chinensis), $5 \mathrm{~m}$ from the roof, and all recorded observations were within a $10-\mathrm{m}$ radius of this roost (Figure $\mathrm{S} 1$ ). Vegetative cover in this area was limited, providing optimal conditions for behavioral observation. Although we color-banded 33 birds (14 males and 19 females) at the beginning of the month, only 28 banded individuals were seen at least once from 15 to 29 November, and only 22 banded individuals ( 8 males and 14 females) remained for the entire range of days. Three factors may have reduced the number of individuals over the course of our study. A suspected fission of the covey- 6 birds disappeared over the first 5 days of observation-one male ( $\delta 1561$ ) of which Roth rediscovered in late January $400 \mathrm{~m}$ or less from his original roost, paired with a female ( 1563$)$ that had vanished prior to the 15-29 November observation period. Also possible are mortality and a fall shuffle i.e., a period of movement between summer and winter ranges, as individual quail regroup to form coveys (Agee 1957), although Johnsgard (1973) reported little exchange of covey members during the fall shuffle. We estimate that there were about five individuals we were unable to trap and band, given that Roth never saw more than three unbanded individuals at once and never saw more than three unbanded males or more than two unbanded females at the same time.

Roth recorded all copulation attempts, successful attempts defined as those including cloacal contact (i.e., a "cloacal kiss"). We defined unsuccess- 
ful copulation attempts as mounting without cloacal contact. We classified females as resisting copulation attempts, regardless of whether the attempt was successful or unsuccessful, when a female was observed struggling to free herself from under the male.

In addition to recording copulation attempts, Roth made three 5-minute focal observations of the 22 individuals that were present for the entire 15-29 November period. During one of the observations of three quail, the focal bird did not associate with any other individual, so Roth made an additional fourth 5 -minute observation of each of these individuals so that we had 15 minutes of association data across all individuals. From these focal observations we estimated the relative amount of time each individual spent with each other bird of the opposite sex. The focal observations took place whenever birds were visible (i.e., when they were at our study site and not inside their roost) between 05:30 and 16:30 Pacific Standard Time. We randomized the order in which individuals were followed, and we never sampled an individual more than once per day. Roth recorded the order and identities of all individuals with which the focal bird associated during each focal observation. We defined associations as instances in which the focal individual came within one body length of another quail, as most of the California Quail's social interactions occur within this distance. Whitehead and Dufault (1999) and Whitehead (2008) recommended that individuals be scored as associating if they are within a distance in which interactions typically occur. Birds often associated with the same individual more than once over the course of a focal observation. We considered all associations between heterosexual pairs, regardless of whether the focal bird was male or female.

Our work was authorized under permit SC 949 from the California Department of Fish and Wildlife and approved by the University of Florida's institutional animal care and use committee (permit 201910744).

\section{RESULTS}

Roth observed three attempted copulations, one successful and two unsuccessful. On 24 November 2019 at 14:09, an unbanded male attempted an unsuccessful copulation with $\$ 002$, which was $>1$ year old. The unbanded male grasped the nape of 9002 's neck with his beak and attempted to mount her. The female immediately resisted the attempt and was able to free herself from under him almost instantaneously. She had been feeding prior to the attempted copulation and quickly resumed foraging. After just a couple of minutes, however, ${ }^{\lambda} 1558,<1$ year old, mounted $\$ 002$ and successfully copulated with her at 14:11. Unlike before, $\$ 002$ did not resist the copulation attempt. With $\lesssim 1558$ firmly on top of her back and grasping the nape of her neck with his beak, +002 raised her tail to facilitate clocal contact. This activity was relatively quick, lasting $\sim 5$ seconds. Both copulation attempts on 24 November 2019 occurred in roughly the same location, within $\sim 0.5 \mathrm{~m}$ of the roost where there was no vegetative cover directly overhead (Figure S1).

On 26 November 2019 at 07:28, Roth observed an unsuccessful copulation attempt between $\delta 1550$ and $q 1547$, both $<1$ year of age. The male mounted the female and trod on her back, repeatedly lifting each foot briefly, as he attempted to secure a firm hold on the female's nape with his beak. The female 


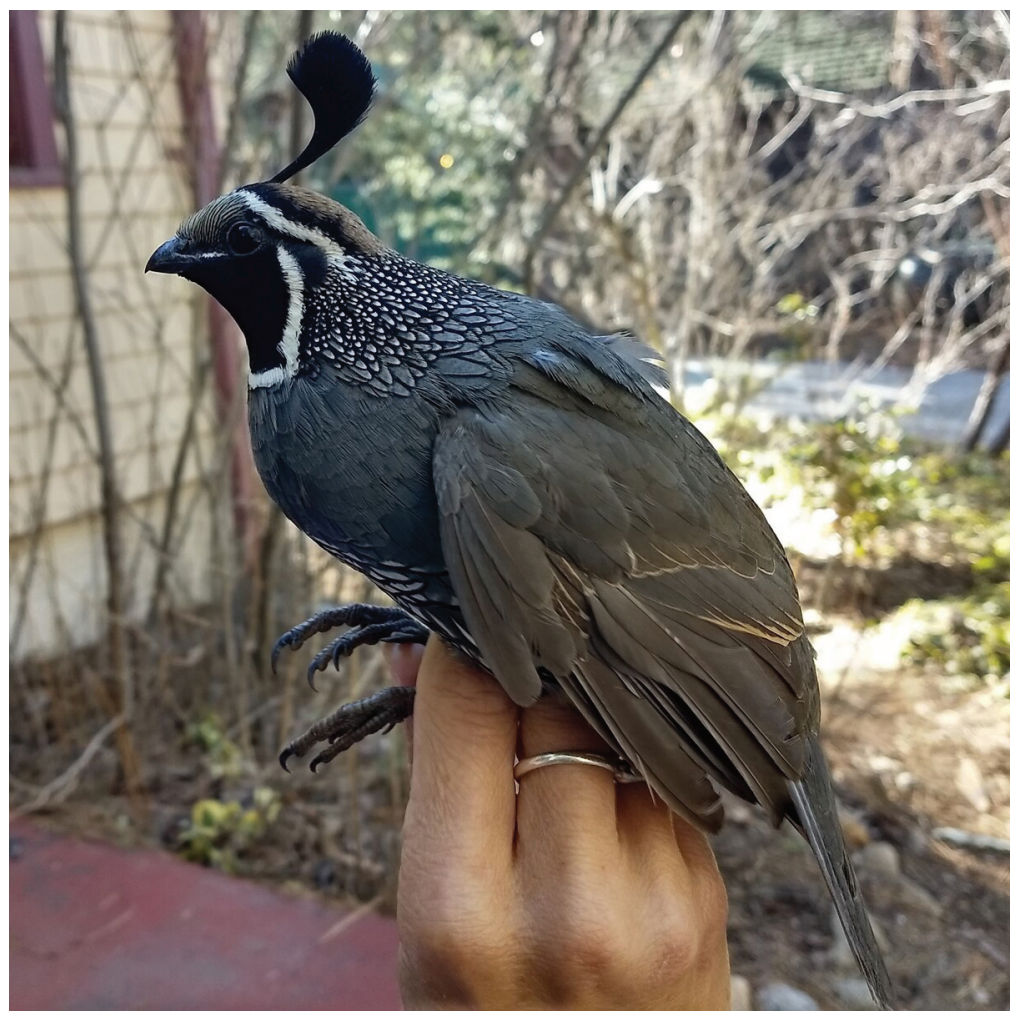

FIGURE 1. Male California quail with mottled primary coverts ( $<1$ years old) in the hand.

Photo by Allison M. Roth

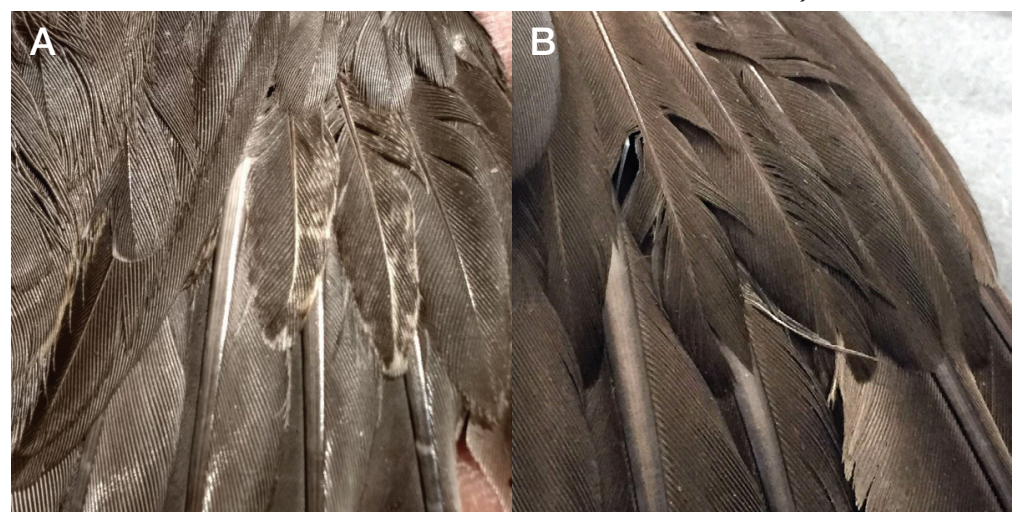

FiguRE 2. Detail of primary coverts of the California Quail. (A) Mottled coverts of an immature; (B) uniform gray coverts of an adult.

Photos by Jennifer M. Gee and Philip Unitt 
did not resist the attempt. She remained still, adopting a crouched position, while ${ }^{\wedge} 1550$ tried to gain balance. Nevertheless, after $\sim 15$ seconds, $\$ 1550$ dismounted 91547 , and cloacal contact never occurred. This last copulation attempt took place within $\sim 2.5 \mathrm{~m}$ of the roost and within $\sim 0.25 \mathrm{~m}$ of the base of a cholla cactus (Cylindropuntia spp.) with several overhanging limbs providing slight overhead cover (Figure S1). All observed copulation attempts occurred in the presence of other members of the covey while the covey was feeding on scattered seed. Furthermore, while female California Quail sometimes solicit copulations by emitting quiet sexual calls while crouching in front of a male (Raitt 1960, Leopold 1977, Calkins et al. 2014), we did not observe any solicitation by either $\$ 002$ or $\$ 1547$.

In addition to the activity described, we also observed an isolated incident of tidbitting at 06:57 on 23 November 2019, between two birds both $<1$ year old ( $\$ 001$ and +1566$)$. While vocalizing, $\$ 001$ repeatedly picked up and dropped an unknown item of food in front of $\$ 1566$, which she then consumed. We did not record the exact location of this interaction, but as with all observations, it occurred within a 10 -m radius of the roost.

Of the 14 females present for the full 15-29 November 2019 observation period, $\$ 1550$ and $\$ 1558$ were each seen associating with 6 (Table 1; see Table S1 at https://archive.westernfieldornithologists.org/archive/V52/ Roth_Appendix for the full heterosexual association matrix). Both 01550 and 1558 associated with the females with which they attempted to copulate (i.e., +1547 and +002 , respectively) more than they associated with any other female (Table 1). The reverse was also true. While +1547 and +002 both were seen associating with four of the eight males that were present for the entire observation period, +1547 associated more with $\delta^{\lambda} 1550$, and +002 more with $\checkmark 1558$, than with any other male (Table 2). $\delta 1550$ associated with $\$ 1547$ $6.67 \times$ more than with the female he spent the second greatest amount of time with; 1558 associated with $90021.57 \times$ more than with the female he spent the second greatest amount of time with. Conversely, $\$ 1547$ associated with $\$ 15506.67 \times$ more than with the male she spent the second greatest amount of time with, and 9002 associated with $15582.75 \times$ more than with the male she spent the second greatest amount of time with.

\section{DISCUSSION}

In a banded covey of California Quail living in the Anza-Borrego Desert, California, we observed three instances of copulatory behavior out of season in autumn. Although we did not see any female solicitation, which sometimes occurs during the normal breeding season, the copulatory behaviors we report are consistent with descriptions of those during the breeding season (Raitt 1960, Leopold 1977, Calkins et al. 2014). Furthermore, the copulatory activity we observed occurred while other members of the covey were feeding in close proximity. Our observations match Raitt's (1960) findings that, during the breeding season, pairs are more likely to copulate in the presence of feeding conspecifics. Nevertheless, Leopold (1977) relayed a personal observation by $\mathrm{M}$. Erwin that copulations are more likely to take place in isolation.

Might the observed copulatory behavior have functioned as an expression of intersexual social dominance, rather than serving to confer any reproduc- 
TABLE 1 Association Matrix between $\lesssim 1550$ and $\lesssim 1558$ and Their Female Covey Mates ${ }^{a}$

\begin{tabular}{|c|c|c|}
\hline & 1550 & 1558 \\
\hline$q 002$ & 0 & 11 \\
\hline 1546 & 0 & 5 \\
\hline q 1547 & 20 & 0 \\
\hline 1548 & 0 & 3 \\
\hline 1553 & 1 & 0 \\
\hline 1554 & 3 & 7 \\
\hline 1564 & 0 & 0 \\
\hline 1565 & 0 & 0 \\
\hline 1566 & 2 & 3 \\
\hline 1568 & 0 & 0 \\
\hline 1569 & 0 & 0 \\
\hline 1570 & 0 & 0 \\
\hline 1571 & 1 & 0 \\
\hline 1573 & 1 & 6 \\
\hline
\end{tabular}

${ }^{a}$ Of females present throughout the observation period, 15-29 November 2019. Each association of a dyad during a focal observation was given a score of 1 . Rectangles indicate dyads in which copulatory activity was seen. Dark gray shading represents the female with which each male spent the most time associating; light gray shading represents the female with which each male spent the second most time associating.

tive benefit, whether immediate or delayed? Although the California Quail's social hierarchies are believed to be sex-specific (Calkins et al. 2014), we did observe eight instances of males directing aggression toward females. Nevertheless, none of these aggressive interactions occurred between the birds we saw copulating. As in other Galliformes (e.g., Persaud and Galef 2003, Løvlie and Pizzari 2007, Roth et al. 2021), these interactions could have been a form of sexual harassment. And although we recorded 33 instances of male-male aggression and 24 instances of female-female aggression, we recorded no same-sex mounting. Moreover, aggression implies no reason for cloacal contact, as was the case in the successful copulation observed between $\lesssim 1558$ and 9002 . Thus, while we cannot completely rule out the possibility that the observed copulatory activity functioned as an expression of intersexual social dominance, that explanation seems implausible.

Both $\lesssim 1550$ and $\precsim 1558$ were under a year of age, as was $\$ 1547$, so none had yet participated in their first breeding season. Therefore, in at least two of the three copulation attempts we observed, the activity could not have functioned to maintain bonds between previously mated pairs (although +002 could have been paired with the unbanded male, whose copulation attempt she resisted, during a previous breeding season). Moreover, because both male and female California Quail reach sexual maturity at 10 months of age, just in time for the beginning of spring breeding (Leopold 1977), it is highly unlikely that $11550, \gamma 1558$, and 91547 were sexually mature at the time of the reported copulatory behavior, and it is reasonable to assume that copulation attempts involving these individuals were not intended to produce offspring. Further- 
TABLE 2 Association Matrix between $q 1547$ and $\$ 002$ and Their Male Covey Mates ${ }^{a}$

\begin{tabular}{|c|c|c|}
\hline & +1547 & $\uparrow_{002}$ \\
\hline 001 & 1 & 2 \\
\hline ఫ005 & 0 & 0 \\
\hline 1550 & 20 & 0 \\
\hline 1551 & 0 & 0 \\
\hline 1552 & 0 & 4 \\
\hline 1555 & 3 & 0 \\
\hline 1558 & 0 & 11 \\
\hline 1567 & 1 & 1 \\
\hline
\end{tabular}

${ }^{a}$ Of males present throughout the observation period, 15-29 November 2019. 9002 also associated with ${ }^{\lambda} 1561$ four times, but

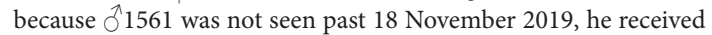
only a single focal observation and cannot be compared to males that received three focal observations. Each association of a dyad during a focal observation was given a score of 1 . Rectangles indicate dyads in which copulatory activity was seen. Dark gray shading represents the male with which each female spent the most time associating; light gray shading represents the male with which each female spent the second most time associating.

more, although Compton (1931) documented the sighting of California Quail chicks, thought to be $\sim 10$ days old, in early January, implying laying in early December, he posited that these chicks were a product of an astonishingly late clutch, rather than an early one. This suggests that even if $\lambda 1550, \lambda 1558$, and 1547 had been sexually mature, it is improbable that they would have copulated for reproduction for the first time months before the start of the breeding season. Similarly, the male-initiated copulation attempts we report could not have arisen as a result of post-nuptial regeneration of the interstitial cells of the testes, as $\curvearrowright 1550$ and $\lesssim 1558$ had not yet participated in their first breeding season. Furthermore, unlike some Galliformes, such as the Ringnecked Pheasant (Phasianus colchicus; Kirkpatrick and Andrews 1944, Hiatt and Fisher 1947) and domestic chickens (Gallus gallus domesticus; Parker et al. 1942), in which precocious spermatogenesis has been recorded in juveniles, California Quail have shown no evidence of initiating spermatogenesis before $\sim 9$ months of age (Lewin 1963). Thus it is highly unlikely that the observed copulatory activity was intended for immediate reproduction, given that these three interactions would reflect the earliest recorded reproductive attempts in California Quail, by far, and it is almost certain that one of the females and at least two of the males were sexually immature.

One question that arises is whether the copulatory activity observed in our study was a way for sexually immature individuals to practice mating prior to the breeding season. To the best of our knowledge, there have been no studies to suggest that sexually immature birds practice copulation, although male Java Sparrows (Lonchura oryzivora) rehearse courtship dances prior to sexual maturity (Soma et al. 2019). Nevertheless, if the observed copulatory activity functioned solely as a means for immature birds to practice the mechanics of copulation, it seems odd that +002 , a sexually mature female, would have 
allowed 1558 to copulate with her successfully, given the costs associated with mating (e.g., increased risk of predation, sexually transmitted diseases; Magnhagen 1991, Lehtonen et al. 2012).

As intersexual dominance, early reproduction, and practice are highly improbable explanations for the observed copulatory activity, we suggest that a more likely explanation is that at least two of the three observed copulation attempts acted to assist in pair formation. This idea is further supported by our finding that, of the individuals whose identities were known, birds of both sexes spent more time with the individuals with which they engaged in copulatory activity than with any other bird of the opposite sex. During the breeding season, a positive correlation between the frequency with which a pair associates and their probability of mating or producing offspring has previously been demonstrated in quail, as well as in another galliform, the Red Junglefowl (Gallus gallus; McDonald et al. 2019, Zonana et al. 2021, Roth et al. 2021). Stronger prebreeding pair bonds may impart benefits including, but not necessarily limited to, earlier or enhanced reproductive synchrony between mated pairs, increased winter survival, and/or a reduction of loss of a partner via death or divorce (Butterfield 1970, Rowley 1983, Ens et al. 1996, Kellam 2003, Culina et al. 2015). Autumn copulatory activity may be one mechanism that assists in the formation of such bonds. Nevertheless, it is reasonable to assume that, for many individuals, pair bonds are not fully established months in advance of the breeding season, and individuals may sample a variety of partners prior to settling on a social mate (Firth et al. 2018). The back-to-back copulatory activity seen between +002 and an unbanded male then $\$ 1558$ may suggest that +002 was still in the process of sampling potential mates. Furthermore, it may be beneficial for individuals to form social bonds with more than one member of the opposite sex (Beck et al. 2020), given that the California Quail's mating system is not sexually monogamous (Leopold 1977, Calkins et al. 2014). Nevertheless, $\$ 002$ resisted the copulation attempt by the unbanded male, prior to allowing 01558 to copulate with her successfully, suggesting a preference for $\$ 1558$. We unfortunately have no way of knowing the proportion of time with which $\$ 002$ spent with the unbanded male, as there was more than one unbanded male present during our study.

Additional evidence suggesting that California Quail may pair during the autumn lies in the tidbitting we observed. Widespread among the Galliformes, tidbitting is a form of courtship feeding believed to assist in pair bonding (Williams et al. 1968, Calkins et al. 2014). Like the copulating pairs, the individuals involved in this tidbitting associated more with each other than with any other covey member of the opposite sex (Table S1).

Although autumn copulatory behavior of immature California Quail may assist in pair formation, it remains possible that these interactions served no immediate adaptive value. The observed copulatory activity may simply be a reflection of the competitive sexual environment in which these quail live, causing the birds to be prepared to seek out any potential chance for copulation, regardless of whether or not fertilization is possible. Furthermore, although we present evidence to support pair formation as the function of the observed copulatory activity, our sample size is extremely limited, and other potential functional explanations cannot be eliminated with certainty.

Most information regarding breeding of the California Quail comes from 
nesting records and observations of the timing of covey breakup. Thus it is possible that autumn copulatory behavior in this species has previously been underestimated, as nesting records can only capture the proportion of autumn copulations that serve an immediate reproductive function. A more intensive investigation of autumn mating patterns in wild California Quail is needed for the potential causes and consequences of this activity to be better understood.

\section{ACKNOWLEDGMENTS}

We extend our gratitude to Robert Theriault, Emily S. Durkin, Karen DeLorenzo, Tony Harper, Elaine Tulving, Tori Kang, and Sicco H. Rood for assistance in the field. Thanks to Steele/Burnand Anza-Borrego Desert Research Center (doi: 10.21973/ N3Q94F), and its reserve manager Jim Dice, and James San Jacinto Mountains Reserve (doi: 10.21973/N3KQ0T) for logistical support. Special thanks to Eleanor Shimeall for letting Roth use her yard for our work, providing Roth and Durkin lodging, and for permitting Roth access to her roof for data collection. Furthermore, we thank Eleanor Shimeall's children, grandchildren, and great-grandchildren for their willingness to work around Roth's field schedule, especially Doska Ross, Scott Shimeall, and Briana, Mike, Kellen, and Soraya Puzzo. We also extend our appreciation to Karen and Tony DeLorenzo for alerting us that $\delta 1561$ and $q 1563$ had relocated to their yard and for allowing us to trap on their property. We thank Steve and Gaylee Rogers for allowing us access to their easement. We are grateful to Daizaburo Shizuka, Philip Unitt, Antica Culina, James S. Kellam, and two anonymous reviewers for providing feedback on our manuscript. We appreciate Dustin Rubenstein for introducing Gee to Roth and Keiser, thereby making this collaboration possible. Roth was funded by the Paul Jorgensen Bird Research Grant, provided by the Anza-Borrego Foundation.

\section{LITERATURE CITED}

Adkins-Regan, E. 2005. Hormones and Animal Social Behavior. Princeton Univ. Press, Princeton, NJ.

Agee, C. P. 1957. The fall shuffle in central Missouri Bob-whites. J. Wildl. Mgmt. 21:329-335; doi.org/10.2307/3796553.

Anthony, R. 1970. Ecology and reproduction of California Quail in southeastern Washington. Condor 72:276-287; doi.org/10.2307/1366004.

Beck, K. B., Farine, D. R., and Kempenaers, B. 2020. Winter associations predict social and extra-pair mating patterns in a wild songbird. Proc. Royal Soc. B 287:20192606; doi.org/10.1098/rspb.2019.2606.

Brennan, P. L., and Prum, R. O. 2012. The limits of sexual conflict in the narrow sense: New insights from waterfowl biology. Philos. Trans. R. Soc. Lond. B, Biol. Sci. 367:2324-2338; doi.org/10.1098/rstb.2011.0284.

Butterfield, P. A. 1970. The pair bond in the Zebra Finch, in Social Behaviour in Birds and Mammals (J. H. Crook, ed.), pp. 249-278. Academic Press, London.

Calkins, J. D. 2000. Dynamic mate choice and mating behavior in California Quail. Ph. D. dissertation, Univ. of Calif., Irvine.

Calkins, J. D. 2007. The family behavior of California Quail: A molecular analysis. Condor 109:962-967; doi.org/10.1093/condor/109.4.962.

Calkins, J. D., Gee, J. M., Hagelin, J. C., and Lott, D. F. 2014. California Quail (Callipepla californica), in Birds of the North America (A. F. Poole, ed.), no. 473. Cornell Lab Ornithol., Ithaca, NY; doi.org/10.2173/bow.calqua.01.

Compton, L. V. 1931. An unusual date for the occurrence of the young of the California Quail. Condor 33:249-249. 
Culina, A., Lachish, S., and Sheldon, B. C. 2015. Evidence of a link between survival and pair fidelity across multiple tit populations. J. Avian. Biol. 46:507-515; doi. org/10.1111/jav.00661.

Emlen, J. T., and Lorenz, F. W. 1942. Pairing responses of free-living Valley Quail to sex-hormone pellet implants. Auk. 59:369-378; doi.org/10.2307/4079206.

Ens, B. J., Choudhury, S., and Black, J. M. 1996. Mate fidelity and divorce in monogamous birds, in Partnerships in Birds: The Study of Monogamy (J. M. Black ed.), pp. 344-401. Oxford Univ. Press, New York.

Firth, J. A., Cole, E. F., Ioannou, C. C., Quinn, J. L., Aplin, L. M., Culina, A., McMahon, K., and Sheldon, B. C. 2018. Personality shapes pair bonding in a wild bird social system. Nat. Ecol. Evol. 2:1696-1699; doi.org/10.1038/s41559-0180670-8.

Francis, W. J. 1965. Double broods in California Quail. Condor 67:541-542; doi. org/10.1002/lipi.19650670724.

Gee, J. M. 2003. How a hybrid zone is maintained: Behavioral mechanisms of interbreeding between California and Gambel's Quail (Callipepla californica and C. gambelii). Evolution 57:2407-2415; doi.org/10.1111/j.0014-3820.2003. tb00252.x.

Hiatt, R. W., and Fisher, H. I. 1947. The reproductive cycle of Ring-necked Pheasants in Montana. Auk 64:528-548; doi.org/10.2307/4080714.

Höhn, E. O. 1947. Sexual behaviour and seasonal changes in the gonads and adrenals of the Mallard. Proc. Zool. Soc. Lond. 117:281-304; doi. org/10.1111/j.1096-3642.1947.tb00519.x.

Johnsgard, P. A. 1973. Grouse and Quails of North America. Univ. of Nebr. Press, Lincoln.

Kellam, J. S. 2003. Pair bond maintenance in Pileated Woodpeckers at roost sites during autumn. Wilson J. Ornithol. 115:186-192; doi.org/10.1676/02-098.

Kirkpatrick, C. M., and Andrews, F. N. 1944. Development of the testis in the Ring-necked Pheasant. Anat. Rec. 89:317-324; doi.org/10.1002/ar.1090890306.

Koenig, W. D., and Stahl, J. T. 2007. Late summer and fall nesting in the Acorn Woodpecker and other North American terrestrial birds. Condor 109:334-350; doi.org/10.1093/condor/109.2.334.

Krakauer, A. H. 2003. California Quail lays egg in Wild Turkey nest. W. Birds 34:169-170.

Lehtonen, J., Jennions, M. D., and Kokko, H. 2012. The many costs of sex. Trends Ecol. Evol. 27:172-178; doi.org/10.1016/j.tree.2011.09.016.

Leopold, A. S. 1977. The California Quail. Univ. of Calif. Press, Berkeley; doi. org/10.1525/9780520907775.

Lewin, V. 1963. Reproduction and development of young in a population of California Quail. Condor 65:249-278; doi.org/10.2307/1365353.

Lott, D. F., and Mastrup, S. N. 1999. Facultative communal brood rearing in California Quail. Condor 101:678-681; doi.org/10.2307/1370200.

Løvlie, H., and Pizzari, T. 2007. Sex in the morning or in the evening? Females adjust daily mating patterns to the intensity of sexual harassment. Am. Nat. 170:E1-E13; doi.org/10.1086/518180.

MacGregor, W. Jr., and Inlay, M. 1951. Observations on failure of Gambel Quail to breed. Calif. Fish and Game 37:218-219.

Magnhagen, C. 1991. Predation risk as a cost of reproduction. Trends Ecol. Evol. 6:183-186; doi.org/10.1016/0169-5347(91)90210-O.

Marshall, A. J. 1952. The interstitial cycle in relation to autumn and winter sexual behavior in birds. Proc. Zool. Soc. London 121:727-740; doi. org/10.1111/j.1096-3642.1952.tb00778.x.

McDonald, G. C., Spurgin, L. G., Fairfield, E. A., Richardson, D. S., and Pizzari, T. 2019. Differential female sociality is linked with the fine-scale structure of 
sexual interactions in replicate groups of Red Junglefowl, Gallus gallus. Proc. Royal Soc. B 286:20191734; doi.org/10.1098/rspb.2019.1734.

McMillan, I. I. 1964. Annual population changes in California Quail. J. Wildl. Mgmt. 28:702-711; doi.org/10.2307/3798785.

Orians, G. H. 1960. Autumnal breeding in the Tricolored Blackbird. Auk 77:379-398; doi.org/10.2307/4082413.

Ostfeld, R. S, and Keesing, F. 2000. Pulsed resources and community dynamics of consumers in terrestrial ecosystems. Trends Ecol. Evol. 15:232-237; doi. org/10.1016/S0169-5347(00)01862-0.

Parker, J. E., McKenzie, F. F., and Kempster, H. L. 1942. Development of the testes and combs of white leghorn and New Hampshire cockerels. Poultry Sci. 21:35-44; doi.org/10.3382/ps.0210035.

Persaud, K. N., and Galef, B. G. Jr. 2003. Female Japanese Quail aggregate to avoid sexual harassment by conspecific males: A possible cause of conspecific cueing. Anim. Behav. 65:89-94; doi.org/10.1006/anbe.2002.2057.

Raitt, R. J. 1960. Breeding behavior in a population of California Quail. Condor 62:284-292; doi.org/10.2307/1365518.

Raitt, R. J., and Genelly, R. E. 1964. Dynamics of a population of California Quail. J. Wildl. Mgmt. 28:127-141; doi.org/10.2307/3797941.

Roth, A. M., Dingemanse, N. J., Nakagawa, S., McDonald, G. C., Løvlie, H., RobledoRuiz, D., and Pizzari, T. 2021. Sexual selection and personality: Individual and group-level effects on mating behavior in red junglefowl. J. Anim. Ecol., doi. org/10.1111/1365-2656.13454.

Rowley, I. 1983. Re-mating in birds, in Mate Choice (P. Bateson, ed.), pp. 331-360. Cambridge Univ. Press, New York.

Selander, R. K., and Nicholson, D. J. 1962. Autumnal breeding of Boat-tailed Grackles in Florida. Condor 64:81-91; doi.org/10.2307/1365478.

Snow, D. W. 1955. The abnormal breeding of birds in the winter 1953/54. Br. Birds 48:120-126.

Soma, M., Iwama, M., Nakajima, R., and Endo, R. 2019. Early-life lessons of the courtship dance in a dance-duetting songbird, the Java Sparrow. Royal Soc. Open Sci. 6:190563; doi.org/10.1098/rsos.190563.

Spurr, E., and Milne, H. 1976. Adaptive significance of autumn pair formation in the Common Eider Somateria mollissima (L.). Ornis Scand. 7:85-89; doi. org/10.2307/3676177.

Sumner, E. L. Jr. 1935. A life history study of the California Quail, with recommendations for its conservation and management. Calif. Fish and Game 21:167-253, 275-342.

Whitehead, H. 2008. Analyzing Animal Societies: Quantitative Methods for Vertebrate Social Analysis. Univ. of Chicago Press, Chicago; doi.org/10.7208/ chicago/9780226895246.001.0001.

Whitehead, H., and Dufault, S. 1999. Techniques for analyzing vertebrate social structure using identified individuals. Adv. Studies Behav. 28:33-74; doi. org/10.1016/S0065-3454(08)60215-6.

Williams, G. R. 1959. Aging, growth-rate and breeding season phenology of wild populations of California Quail in New Zealand. Bird-Banding 30:203-218; doi.org/10.2307/4510776.

Williams, H. W., Stokes, A. W., and Wallen, J. C. 1968. The food call and display of the Bobwhite Quail (Colinus virginianus). Auk 85:464-476; doi. org/10.2307/4083295.

Zonana, D. M., Gee, J. M., Breed, M. D., and Doak, D. F. 2021. Dynamic shifts in social network structure and composition within a breeding hybrid population. J. Anim. Ecol. 90:197-211; doi.org/10.1111/1365-2656.13314. 